\title{
Working memory activation of neural networks in the elderly as a function of information processing phase and task complexity
}

\author{
Céline Charroud ${ }^{\mathrm{a}, \mathrm{b}}$, Jason Steffener ${ }^{\mathrm{c}}$, Emmanuelle Le Bars ${ }^{\mathrm{a}}$, Jérémy Deverdun ${ }^{\mathrm{a}, \mathrm{d}, \mathrm{e}}$, Alain Bonafe ${ }^{\mathrm{a}}$, \\ Meriem Abdennour $^{\mathrm{f}}$, Florence Portet ${ }^{\mathrm{f}, \mathrm{g}}$, François Molino ${ }^{\mathrm{d}, \mathrm{h}}$, Yaakov Stern ${ }^{\mathrm{c}}$, Karen Ritchie ${ }^{\mathrm{f}, \mathrm{i}, \mathrm{j}}$, \\ Nicolas Menjot de Champfleur ${ }^{\mathrm{a}, \mathrm{k}, *, 1}$, Tasnime N. Akbaraly ${ }^{\mathrm{b}, \mathrm{l}, 1}$ \\ a Institut d'Imagerie Fonctionnelle Humaine, I2FH, Department of Neuroradiology, Montpellier University Hospital Center, Gui de Chauliac Hospital, University of \\ Montpellier, Montpellier, France \\ ${ }^{\mathrm{b}}$ Inserm, Unit 1198, Molecular Mechanisms in Neurodegenerative Diseases, University of Montpellier, Montpellier, France \\ ${ }^{\mathrm{c}}$ Cognitive Neuroscience Division, Department of Neurology, Columbia University, New York, United States \\ ${ }^{\mathrm{d}}$ Laboratoire Charles Coulomb, CNRS UMR 5221, University of Montpellier, Montpellier, France \\ ${ }^{\mathrm{e}}$ Intrasense, Montpellier, France \\ ${ }^{\mathrm{f}}$ Inserm, Unit 1061, Neuropsychiatry: Epidemiological and Clinical Research, La Colombière Hospital, University of Montpellier, Montpellier, France \\ ${ }^{\mathrm{g}}$ Montpellier University Hospital, Department of Adult Psychiatry, La Colombière Hospital, Montpellier, France \\ ${ }^{\mathrm{h}}$ Institut de Génomique Fonctionnelle, UMR 5203, INSERM U661, University of Montpellier, Montpellier, France \\ i University of Montpellier, Montpellier, France \\ ${ }^{\mathrm{j}}$ Faculty of Medicine, Imperial College, London, United Kingdom \\ ${ }^{\mathrm{k}}$ Team "Plasticity of Central Nervous System, Stem Cells and Glial Tumors", U1051, Institut of Neurosciences of Montpellier, Saint Eloi Hospital, Montpellier, France \\ ${ }^{1}$ Department of Epidemiology and Public Health, University College London, London, United Kingdom
}

\section{A R T I C L E I N F O}

Article history:

Received 18 May 2015

Revised 25 September 2015

Accepted 1 October 2015

Available online 8 October 2015

\section{Keywords:}

Aging

Functional MRI

Memory: working memory

Neuroimaging

\begin{abstract}
A B S T R A C T
Changes in working memory are sensitive indicators of both normal and pathological brain aging and associated disability. The present study aims to further understanding of working memory in normal aging using a large cohort of healthy elderly in order to examine three separate phases of information processing in relation to changes in task load activation.

Using covariance analysis, increasing and decreasing neural activation was observed on fMRI in response to a delayed item recognition task in 337 cognitively healthy elderly persons as part of the CRESCENDO (Cognitive REServe and Clinical ENDOphenotypes) study.

During three phases of the task (stimulation, retention, probe), increased activation was observed with increasing task load in bilateral regions of the prefrontal cortex, parietal lobule, cingulate gyrus, insula and in deep gray matter nuclei, suggesting an involvement of central executive and salience networks. Decreased activation associated with increasing task load was observed during the stimulation phase, in bilateral temporal cortex, parietal lobule, cingulate gyrus and prefrontal cortex. This spatial distribution of decreased activation is suggestive of the default mode network.

These findings support the hypothesis of an increased activation in salience and central executive networks and a decreased activation in default mode network concomitant to increasing task load.
\end{abstract}

(c) 2015 Elsevier Inc. All rights reserved.

\section{Introduction}

Both normal and pathological brain aging implicate modifications in information processing ability which is notably observed within the functioning of a multicomponent memory system referred to as "working memory" (Baddeley, 1988, 2012). This

* Corresponding author at: Hôpital Gui de Chauliac, Service de Neuroradiologie, 80 avenue Augustin Fliche, 34295 Montpellier cedex 5, France.

E-mail address: nicolasdechampfleur@orange.fr (N. Menjot de Champfleur).

1 T.N. Akbaraly and N. Menjot de Champfleur contributed equally to this work. short-term memory system co-ordinates high level cognitive processes and simultaneous performance of cognitive tasks: agerelated modification in any of its components is significantly associated with decreased performance (Baddeley, Bressi, Sala, Logie, \& Spinnler, 1991; Linden et al., 2003; Park et al., 1996; Zarahn, Rakitin, Abela, Flynn, \& Stern, 2007). The working memory model comprises a "central executive" responsible for information filtering and integration, and two sub-systems manipulating and temporarily maintaining verbal and visual information (the phonological loop and the visuo-spatial sketchpad), and has been 
validated by many decades of empirical clinical observation. It has become one of the principal targets for studies of both normal age-related cognitive changes and neuropathologies such as dementia and depression.

Early animal research on the neuronal and neurotransmitter bases of working memory located it principally in the prefrontal cortex (PFC) (Fuster, 1973). Subsequent PET and fMRI studies in humans have confirmed the central role of the PFC but have further indicated activation throughout the cortex, notably in parietal areas, with spatial and verbal stimuli recruiting principally right and left-hemisphere areas respectively (Smith, Jonides, Marshuetz, \& Koeppe, 1998). Moreover, it has recently been suggested that the PFC may be the principal area associated with information management, with more posterior areas, including the parietal cortex, possibly having a prominent role in information maintenance. This hypothesis has been based on findings that both areas showing increased interactivity during working memory tasks (Curtis \& D’Esposito, 2003; Nee et al., 2013; Rottschy, Caspers, \& Roski, 2013). Recent research aimed at differentiating the brain regions involved in working memory have principally used delayed recognition tasks such as Delayed Item Recognition (DIR) (Coltheart, 2006). These tasks enable the differentiation of the three phases of working memory: target/stimulation, delay/ retention and probe/response covering (i) information recording, allowing rapid conversion of visual (or auditory) space into phonological code, and initialization of the phonological loop whether the memorandum allow a verbalization, (ii) the consolidation of articulatory rehearsal, in order to reiterate the phonological loop and actively maintain the memory trace, (iii) retrieval of stored information and its use in decision-making processes.

Functional MRI studies of DIR tasks (Manoach, Greve, Lindgren, \& Dale, 2003; Marvel \& Desmond, 2010; Nystrom et al., 2000) have reported specific activation of several brain regions for each of the three phases of working memory functioning: parietal lobules, ventrolateral and dorsolateral prefrontal cortex, precentral gyrus, deep gray matter nuclei, cingulate gyrus, temporal lateral cortex and occipital cortex during the stimulation and retention phase and ventrolateral prefrontal cortex, insula and deep gray matter nuclei during the probe phase. (Cairo, Liddle, Woodward, \& Ngan, 2004; Chen \& Desmond, 2005). While previous research has principally focused on differentiating activation associated with specific working memory phases, more recent work has begun to explore the consequences on neural activity of increasing DIR task difficulty. To date, two studies (Ansado et al., 2013; Zarahn et al., 2007) of neural network activation (task load) associated with increased task difficulty, comparing older and younger healthy individuals found that older individuals demonstrate increased neural activation with increasing load for the same level of performance compared to younger adults. Two case control studies comparing healthy older and younger adults (Sambataro et al., 2010) and mild cognitive impairment and Alzheimer's disease subjects (Rombouts, Barkhof, Goekoop, Stam, \& Scheltens, 2005) observed decreased neural activity with increasing DIR task difficulty in the medial prefrontal cortex, posterior cingulate/retrosplenial cortex, inferior parietal lobules and superior and inferior temporal cortex. These areas are described as part of the default mode network (Greicius \& Menon, 2004), a network involved in judgment, retrieval and manipulation of episodic memory and semantic knowledge (Greicius, Krasnow, Reiss, \& Menon, 2003), selfreferential processing (Gusnard \& Raichle, 2001) and mind wandering (Christoff, Gordon, Smallwood, Smith, \& Schooler, 2009). The principal shortcoming of previous studies of working memory in the elderly has been the small number of subjects, and given the heterogeneity of elderly persons in relation to health-related variables, it is not surprising that there has been considerable inconsistency in the findings.
The aim of the present research is to extend knowledge of the multiple and concomitant cognitive processes involved in the maintenance of normal working memory in healthy elderly persons by studying each phase of information processing in working memory in relation to increasing/decreasing task load activation. The study is carried out in a much larger elderly cohort than has previously been examined, thus reducing bias due to sample selection.

\section{Methods}

\subsection{Cohort}

The data were derived from the on-going prospective Montpellier-Three-City study (The 3C Study Group, 2003) in which 2259 volunteers (recruited from the electoral rolls), aged 65 years and older, underwent standardized neurological examinations in a dedicated clinical research facility. The clinical examinations were undertaken at baseline (1999-2001) and 2, 4, 7, 10 and 12 years. At 12-year follow-up, participants who were free of dementia and had a Mini Mental State Examination MMSE (Folstein, Folstein, \& McHug, 1975) score over 24 were invited to undergo an MRI and complementary clinical examination as part of the CRESCENDO (Cognitive REServe and Clinical ENDOphenotype) study $(n=380)$. The clinical examination for CRESCENDO participants was carried out approximately 8 months before the MRI examination. Subjects were only able to participate if able to travel to the clinical center and did not have any contraindication for the MRI examination. The diagnosis of dementia was based on a 3-step procedure. First, trained psychologists administered a battery of neuropsychological tests detailed elsewhere (Akbaraly et al., 2009). Second, all the participants were then examined by a neurologist, Finally, an independent committee of neurologists reviewed all potential prevalent and incident cases of dementia to obtain a consensus diagnosis according to the criteria of the Diagnostic and Statistical Manual of Mental Disorders, fourth edition (American Psychiatric Association, 2000). Similar procedures were performed at each phase over the 12-years of follow-up for incident dementia screening. Cases of $\mathrm{AD}$ were classified according to the National Institute of Neurological and Communicative Disorders and Stroke-Alzhei mer's Disease and Related Disorders Association (McKhann et al., 1984) and cases of mixed/vascular dementia according to the National Institute of Neurological Disorders and Stroke - Association Internationale pour la Recherche en l'Enseignement en Neurosciences criteria (Román et al., 1993).

The study was carried out at the neuroradiology department of the Montpellier University Hospital Human Functional Imaging Institute (I2FH), France. The study protocol was approved by the ethics committee of the University-Hospital of Bicêtre, and written informed consent was obtained from each participant. Characteristics of the 380 CRESCENDO participants have been compared to the characteristics of dementia-free participants of the MontpellierThree-City study who underwent the 12 -y follow-up examination but who were not included in the CRESCENDO study. Recorded clinical data were: laterality (Edinburgh handedness inventory), Body Mass Index, educational level, current lifestyle, MMSE and cardiovascular disease.

\subsection{Delayed item recognition task}

Working memory was assessed by a DIR task using letter stimuli (Sternberg, 1966), schematized in Fig. 1 (Zarahn et al., 2007). Each trial of the DIR task consisted of 3 phases: stimulation, retention and probe. The stimulation phase is based on the presentation over $3 \mathrm{~s}$ of an array of one, three or six capital letters (the number 


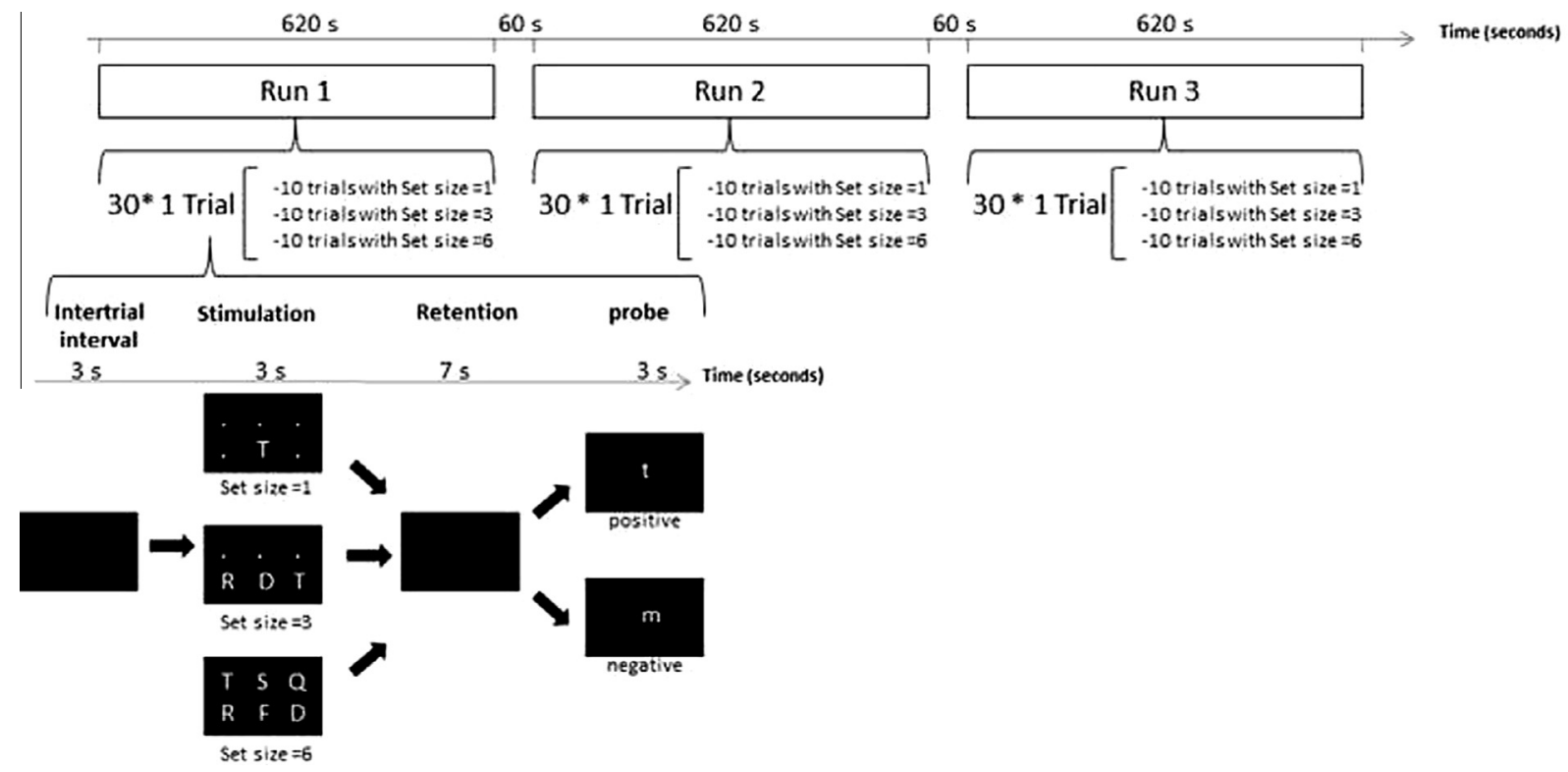

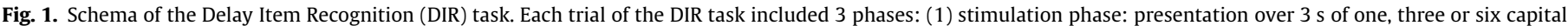

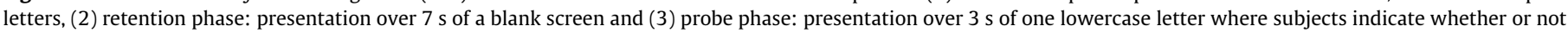

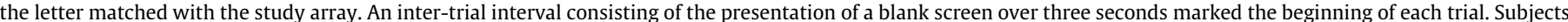

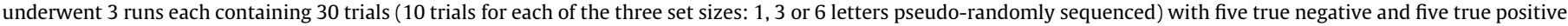
probes per set.

of letters being the set size) the participants having been instructed to remember these letters. During the retention phase, participants were instructed to focus their gaze on the blank screen during $7 \mathrm{~s}$ and hold the stimulus items in mind. In the probe phase, a lowercase letter is shown in the center of the screen for three seconds, participants indicate by pressing a button whether or not the probe matched a letter in the study array (right index finger button press to indicate 'yes', left index finger button press to indicate 'no'). An inter-trial interval consisting of the presentation of a blank screen for three seconds marked the beginning of each trial. In addition, 70 blank trials (presentation of a blank screen for $2 \mathrm{~s}$ ) were pseudo-randomly interspersed between trials in each run to reduce the likelihood of neurophysiological responses predictive of the beginning of trials. As indicated in Fig. 1, participants underwent 3 runs each containing 30 trials ( 10 trials for each of the three set sizes: 1,3 or 6 letters pseudo-randomly sequenced via a random-without-replacement scheme.) with five true negative and five true positive probes per set size. Participants were instructed to respond as accurately as possible. No feedback about performance accuracy was given during the scanning session.

DIR task performance is analyzed according to 3 phases representing (1) the encoding process during the stimulation phase; (2) maintenance processes during retention and (3) the retrieval process during the probe phase. The number of letters determines the level of stimulus difficulty, thus differentiating memory-load level. Before fMRI acquisition, participants were trained on at least 2 DIR runs of 30 trials each (the first one of which was administered with feedback) on a computer with the help of a neuropsychologist. Vision correction was performed by an ophthalmologist using nonmagnetic glasses in the range of -5 to +3 with 0.5 diopter steps (MediGlasses, Cambridge Research Systems).

\subsection{Magnetic resonance imaging data acquisition}

Task stimuli were back-projected onto a screen located at the foot of the MRI bed using an LCD projector. Participants viewed the screen via a mirror located in the head coil. Task responses were made on a NordicNeuroLab system (Bergen, Norway, www. nordicneurolab.com) and behavioral data were recorded on the task computer. Task onset was electronically synchronized with the MRI acquisition computer with the NordicNeuroLab SyncBox. Task administration and data collection (response time and percentage of correct responses) were controlled using publicly available code (https://github.com/steffejr/InterferenceLetterSternberg) developed using Psychotoolbox (http://psychtoolbox.org/PsychtoolboxDownload). Following the scanning session, DIR task performance (response time and percentage of correct responses) was recorded for each level of difficulty. MatLab software (The Mathworks Inc.; MA, USA, R2012a) was used for visual stimulus presentation and recording responses.

Whole brain functional MR images were acquired using a 3Tesla magnet (Skyra, Siemens, Erlangen, Germany) equipped with a 32-channel receive-only head coil. Three hundred sixteen volumes of BOLD Gradient Echo-echo planar images (GE-EPI) were obtained during the functional MRI Sternberg Task with the following imaging parameters: $\mathrm{TR}=2000 \mathrm{~ms}, \mathrm{TE}=20 \mathrm{~ms}, 39$ axial slices, slice thickness $3 \mathrm{~mm}$, slices order: interleaved, in plane resolution $2.39 \times 2.39 \mathrm{~mm}^{2}$, no interslice gap, interleaved, flip angle $90^{\circ}$. The slices covered the whole brain extending from vertex to the upper parts of the cerebellum. For all participants, high-resolution anatomical images were acquired using a 3D magnetizationprepared, rapid acquisition gradient echo (MP-RAGE) sequence with the following parameters: $T R=1690 \mathrm{~ms}$; $T E=2.54 \mathrm{~ms}$; $\mathrm{TI}=922 \mathrm{~ms}$; Flip angle $9^{\circ}$, aligned with the corpus callosum; voxel size: $1 \times 1 \times 1 \mathrm{~mm}$; with 176 slices. Magnitude and phase images of the magnetic field were acquired with a gradient echo-echo planar (GE-EPI) sequence $(\mathrm{TR}=436 \mathrm{~ms}, \mathrm{TE} 1=4.92 \mathrm{~ms}$, TE2 $=7.38 \mathrm{~ms}$, voxels size: $2.56 \times 2.56 \times 3 \mathrm{~mm}$, flip angle $60^{\circ}$ ).

\section{4. fMRI data pre-processing}

Statistical Parametric Mapping (SPM8; Wellcome Department of Imaging Neuroscience, London, UK, http://www.fil.ion.ucl.ac. uk/spm/software/spm8/) (Ashburner, 2012) was used as implemented in MatLab (The Mathworks Inc.; MA, USA, R2012a) for image preprocessing and statistical analyses. 
It included corrections of magnetic field distortion, scan acquisition time difference and head motion. Co-registration to the individual anatomical image was then performed. The anatomical images were segmented into gray matter, white matter, and cerebrospinal fluid using a unified segmentation algorithm as implemented in the "New segment" function of SPM8. A customized template was created based on the gray matter segmentations using a Diffeomorphic Anatomical Registration Through Exponentiated Lie Algebra (DARTEL) (Ashburner, 2007). Using this procedure, the anatomical images of each subject were normalized with the created template, and then a mean image of all normalized 3DT1 was performed. Hence functional images were spatially normalized to the 3DT1 mean image and spatially smoothed using a Gaussian filter with a full width at half maximum of $8 \mathrm{~mm}$ to accommodate inter-individual anatomical variability.

\section{5. fMRI statistical analyses}

\subsubsection{Time-series modeling}

The GE-EPI time-series were modeled in a first level general linear model (Friston et al., 1994) with regressors representing the expected BOLD fMRI response (implicitly, relative to the blank intervals) to the stimulation, retention and probe phases of the task, separately for each block and set size (1, 3 and 6) (Fig. 1). Trials on which there was either an incorrect or no motor response from the participant during the probe phase were modeled separately and not included in the second level analysis. Realignment parameters have been added in the regression models to remove specific activation due to head movement (translations "right", "forward", "up" and rotations "pitch", "roll", "yaw") and a $128 \mathrm{~s}$ high-pass filter was used to remove non-physiological slow signal shifts. Three rectangular functions of duration were used to model neural response: one in the stimulation phase $(3000 \mathrm{~ms})$, one in the retention phase $(7000 \mathrm{~ms})$ and another in the probe phase (3000 ms). Contrasts were estimated for each load level and phase of the task, using a first level general linear model approach. These parametric maps serve as the dependent variables for the subsequent second level covariance analysis (Habeck et al., 2005).

\subsubsection{Covariance analyses}

Ordinal Trend Canonical Variates Analysis (OrtCVA) was performed for the entire cohort to identify a unique pattern of signal covariance, with expression varying with load (i.e. gradual difficulty of the task). This approach is similar to other regional covariance analysis techniques (i.e. Partial Least Squares). It identifies a group-level covariance pattern of task-related brain regions having monotonic increasing (or decreasing) levels of brain activation with increasing task load. This method has been described elsewhere (Habeck et al., 2003, 2005).

A single covariance pattern represents one preferred direction in the vector space determined by the value of activation in each voxel of the image. Neural responses according to increase in difficulty for each subject can thus be represented as moving along this preferred direction with individual differences appearing as a change in the degree of this displacement. Displacement therefore indicates the degree of change in response to increase in difficulty. The aim is then to identify a pattern of covariance including the similarities between three difficulty levels for which the degree of expression may vary. Consequently, this approach does not focus on a particular region or on the activation of one condition of interest, but on changes in regional activation induced by increasing difficulty for each subject.

The first step consists of a principal components analysis to identify the preferred directions of information; each component corresponding to a direction. The Akaike information criterion (AIC) is used to select the most relevant components and indicate privileged directions of interest in the vector space. This criterion, based on the best bias-variance trade-off, can estimate the quality of each model relative to each of the other models (Burnham \& Anderson, 2004) thus aiming to reduce the number of components and describe the data with the lowest possible number of components. The preferred model is the one with the minimum AIC value. Finally, the covariance model corresponds to the linear combination of the selected principal components. The coefficients of this linear combination are obtained by multiple linear regression with the coefficients representing the best linear mean trend across the three levels of difficulty.

The objective of the OrtCVA method is to obtain one wholebrain mapping (at voxel level) whose activations increase and/or decrease with increasing difficulty of the task. The different weights of each voxel are assigned by the obtained linear model. A bootstrap estimation procedure is performed to assess this weight in each voxel of the entire group. A map of the group representing this weight is thus obtained and converted into a $z$ score. For instance, if the weight of the voxel is denoted $w$ and its standard deviation is $s$, the result is: $z=w / s$. By thresholding the map by a $z$-score (e.g. $|z|=2.33$ ), the activation will be obtained with a specific one-tailed probability (e.g., $p<0.01$ ) according to the assumptions of a standard-normal distribution. Thus, the absolute value of weight determines the slope of change. For example, a region whose weight is twice as large as another region indicates that the slope of the activation in this region is twice as high as another region. Positive voxel weights indicate an increased activation with increasing task load while negative voxel weights indicate a decreased activation with increasing task load. The end result of this analysis is a single group level covariance pattern of brain activity demonstrating monotonic changes with increasing task load for each phase of the DIR task. A threshold of $|z|=2.33$ for each phase, corresponding to $p<0.01$, is applied (Habeck et al., 2005; Moeller \& Habeck, 2006).

The property of a monotonic increase/decrease of brain activity with increasing within-subject load is called an "ordinal trend" and quantified by repeated-measures $F$-statistics. It is represented by a $p$-value generated by a random permutation test. The goal of this test is to sample data at least 1000 times with a random subject/condition using the same set of principal components calculated in the first estimation of the model. It provides an additional validation criterion to ensure that the observed covariance model corresponds to activation changes with increasing task load. This test can thus improve the sensitivity of the OrtCVA method without lowering its specificity.

Data quality control may also be carried out by reporting the number of subjects (number of exceptions) that do not follow the linear trend. When the number of exceptions is high, the linear trend is assumed to not be respected. In addition, the significance of the obtained linear model is estimated by a permutation test whose result is a $p$-value. The aim of this permutation test is to switch subjects (1000 times) to assess the number of exceptions to the obtained linear model for each iteration. If the number of exceptions is lower than that the number of exceptions obtained in the first model calculated, the significance increases. Thus, the model will be considered significant if $p<0.05$. Finally, participants that deviate from a monotonic trend are detected and the analysis is not carried out if (1) this occurred for more than $30 \%$ of the entire group, (2) the random permutation test generated a $p$-level higher than 0.05 .

In contrast, the analogous general linear model analysis (using SPM) involves voxel-wise analysis of hemodynamic response between task load. This approach is performed using orthogonal contrast for the linear trend which did not focus on the activation changes across load levels. The information relating to the variability of increasing task load between subjects is not taken into 
account. The OrtCVA method is thus a more stringent validation method than the general linear model in determining pattern variation according to load (D'Esposito, Deouell, \& Gazzaley, 2003; Zarahn, Rakitin, Abela, Flynn, \& Stern, 2006). However, using the OrtCVA method, comparisons between phases and correlations with a parameter (age, performance...) cannot be investigated on brain activation with increasing task load (Moeller \& Habeck, 2006).

\subsubsection{Statistical analyses of behavioral measures}

Kruskall-Wallis non parametric tests were used to compare mean response time and accuracy between each level of task difficulty. Significance was set at $5 \%$, and statistical analyses were carried out with the $\mathrm{R}$ software version 3.0.2. All $p$ values reported were not corrected for multiple testing.

\section{Results}

\subsection{Participant characteristics}

Of the 380 CRESCENDO participants, 337 subjects have been included in the present analysis (35 participants did not complete the DIR task and 8 were removed due to head movements during acquisition). Characteristics of the participants are detailed in Table 1.

As expected, an increase in response time and a decrease in percentage of accurate responses were observed with increasing difficulty of the DIR task. Mean (SD) for response time was: $m=1.04$ $(0.23) \mathrm{s}$ for letter $1, m=1.26(0.24) \mathrm{s}$ for letters 3 and $m=1.50$ $(0.29) \mathrm{s}$ for letters 6 ( $p<0.0001$, two-tailed Kruskal-Wallis test).

Table 1

Characteristics of the 337 CRESCENDO participants.

\begin{tabular}{ll}
\hline Variables & $\begin{array}{l}\text { Participants included in } \\
\text { the analysis of DIR task } \\
N=337\end{array}$ \\
& $184(54.6)$ \\
Women, $n$ (\%) & $81.9(3.7)$ \\
Age at MRI acquisition, mean (SD), years & $16(4.7)$ \\
Laterality, $n$ (\%) & $309(91.7)$ \\
Ambidextrous & $12(3.6)$ \\
Right handed & $24.31(3.3)$ \\
Left handed & \\
BMI, mean (SD), kg/m ${ }^{2}$ & $63(18.7)$ \\
Level of education, $n$ (\%) & $90(26.7)$ \\
Low & $70(20.8)$ \\
Medium low & $114(33.8)$ \\
Medium high & \\
High & $63(18.3)$ \\
Current lifestyle, $n$ (\%) & $274(81.3)$ \\
Alone & $28.62(1.5)$ \\
Couple or living with family members & $77(22.9)$ \\
MMSE, mean (SD) & \\
Cardiovascular disease, $n$ (\%) & $1.04(0.23)$ \\
Response time, mean (SD) & $1.26(0.24)$ \\
Letter 1 & $1.50(0.29)$ \\
Letter 3 & \\
Letter 6 & $0.97(0.05)$ \\
Accuracy, mean (SD) & $0.96(0.07)$ \\
Letter 1 & $0.86(0.11)$ \\
Letter 3 & \\
Letter 6 & \\
\hline
\end{tabular}

Data are mean (SD) or number of subjects (\%). Laterality was assessed by the Edinburgh handedness inventory questionnaire. Education level was classified as low (5 years of schooling or less), medium low (6-9 years), medium high (1012 years), and high (more than 12 years). Cognitive deficit was assessed by the Mini Mental State Examination (cut-off for possible dementia <24). Delayed item recognition task performances (response time and accuracy) are reported in each level of stimulus difficulty determined by the number of letters (Letter 1, Letter 3 and Letter 6).

Abbreviations: BMI, Body Mass Index; MRI, magnetic resonance imaging; MMSE Mini Mental State Examination.
Percentage of accuracy responses were: $m=0.97(0.05)$ for letter $1, m=0.96(0.07)$ for letters 3 and $m=0.86(0.11)$ for letters 6 $(p<0.0001$, two-tailed Kruskal-Wallis test).

\subsection{Covariance analyses}

OrtCVA analyses identified covarying increasing and decreasing activation associated with increasing DIR task difficulty for the three task phases. Examining individual covariance patterns, the majority of participants were observed to show montonic change in expression with increasing task load as assessed by the permutation tests (98\% in the stimulation phase, $88 \%$ in the retention phase, $70 \%$ in the probe phase).

\subsubsection{Increased activation associated with increasing task load}

Changes in neural activation, increasing simultaneously with increasing task difficulty, presumably reflect more effort on the part of subjects to encode, maintain and retrieve information in memory. Across the three phases of the DIR task, brain regions with covarying increased activation are detailed in Fig. 2 and Table 2. During the stimulation phase, we observed bilateral increased activation in the cerebellum (declive and vermis), precentral gyrus and bilateral deep gray matter nuclei (lentiform nucleus and thalamus). During the retention phase, we also observed bilateral increased activation in the cerebellum (culmen, declive, vermis), lateral temporal cortex (left middle and superior gyrus) and bilateral deep gray matter nuclei (caudate nucleus). During the probe phase, we found bilateral increased activation in the fusiform gyrus and bilateral deep gray matter nuclei (lentiform nucleus and thalamus).

Furthermore, some activated regions were similarly observed during the three phases of the DIR task in bilateral frontal lobes (dorsolateral prefrontal cortex, ventrolateral prefrontal cortex and dorsomesial prefrontal cortex), in bilateral parietal lobes (inferior and superior lobule), bilateral cingulate gyrus and bilateral insula.

\subsubsection{Decreased activation associated with increasing task load}

Covarying decreasing neural activation in response to increasing task difficulty, possibly indicating networks that have to be inhibited to maintain an accurate response, was observed over the three phases of the DIR task. Brain regions showing decreased activation associated with increasing task load are given in Fig. 3 and Table 3. During the stimulation phase, bilateral decreased activation was observed in occipital lobes (fusiform gyrus), parietal lobes (superior and inferior lobules), frontal lobes (dorsolateral prefrontal cortex, dorsomesial prefrontal cortex, precentral gyrus), lateral temporal cortex (middle and superior temporal gyrus), cingulate gyrus and insula. During the retention phase we observed decreased activation in the occipital lobes (bilateral lingual gyrus, bilateral cuneus, left fusiform, bilateral middle occipital gyrus and left inferior occipital gyrus), limbic system (bilateral amygdala, bilateral cingulate gyrus and left parahippocampal gyrus), bilateral middle temporal gyrus, bilateral superior parietal lobule and left medial frontal gyrus and in areas of deep gray matter nuclei (bilateral putamen and bilateral thalamus). During the probe phase we found decreased activation in the left medial frontal gyrus, bilateral lingual gyrus, bilateral superior and middle temporal gyrus, bilateral cingulate gyrus and bilateral insula.

\section{Discussion}

The present fMRI study carried out on a large cohort of healthy elderly persons, aimed to explore normal brain response during different information processing phases of a working memory task 


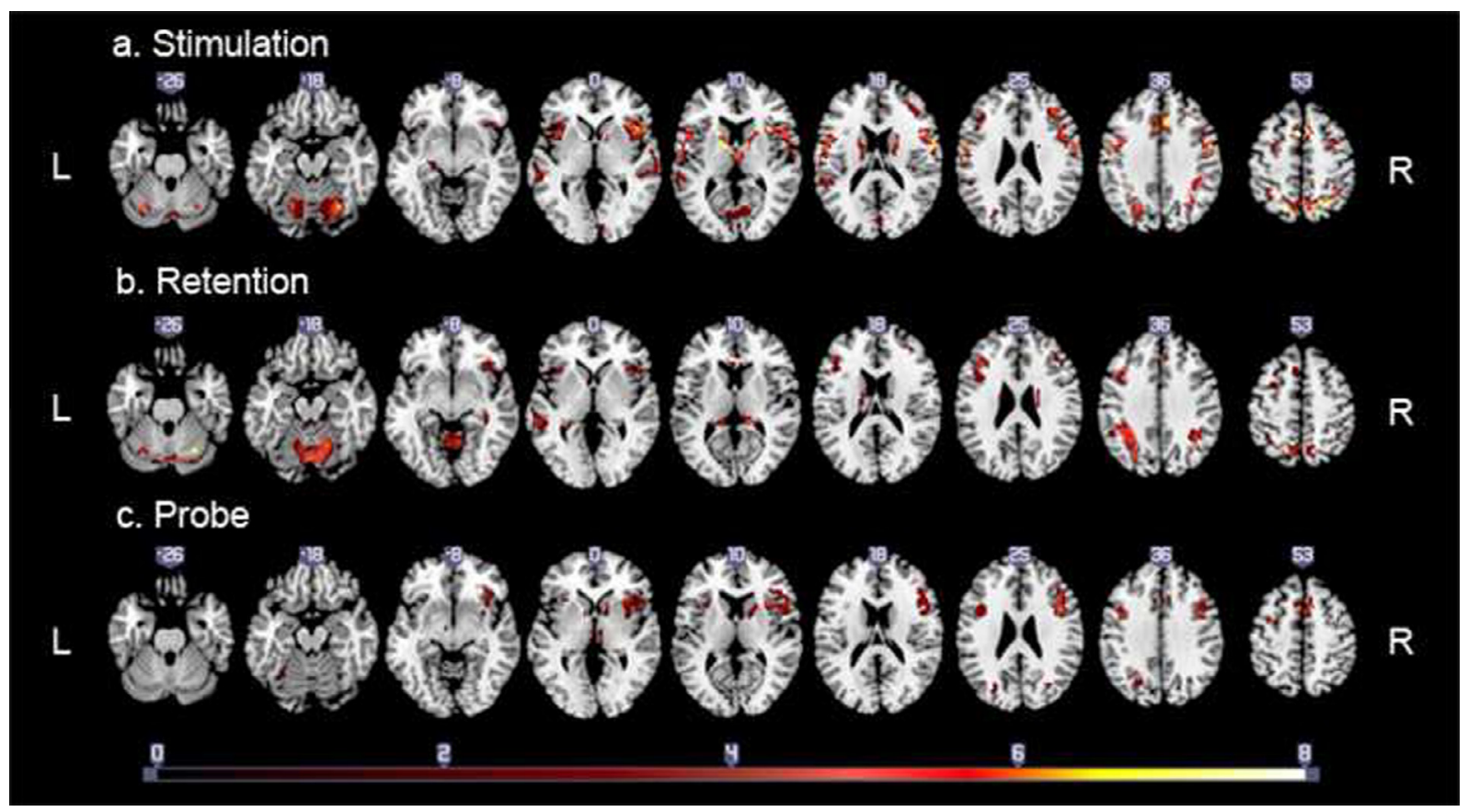

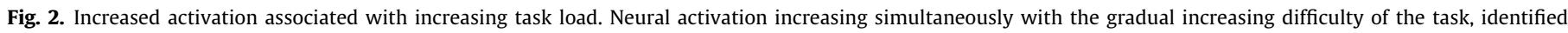

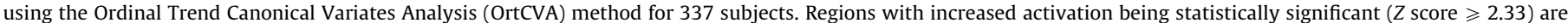

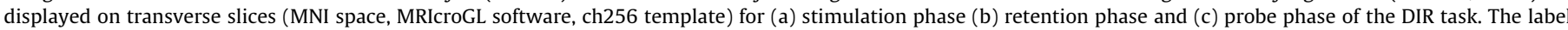

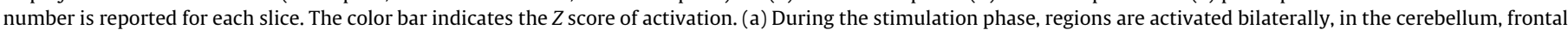

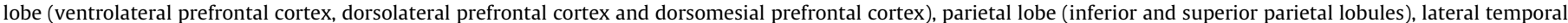

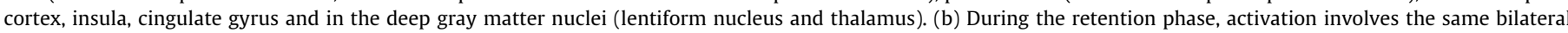

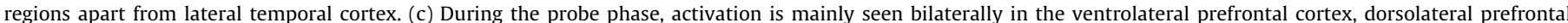

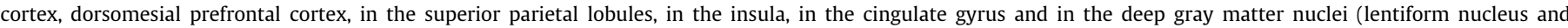
thalamus). (For interpretation of the references to color in this figure legend, the reader is referred to the web version of this article.)

with increasing task difficulty. We found a covarying network of brain regions displayed increased expression associated with increasing task load regardless of the task phase: the bilateral dorsolateral and ventrolateral prefrontal cortex, bilateral dorsomesial prefrontal cortex, bilateral inferior and superior parietal lobule, bilateral cingulate gyrus and bilateral insula. These findings confirm previous observations in younger persons, that mobilization of the working memory system involves predominantly, but not exclusively, PFC areas, with concomitant decreased expression in posterior regions. We found decreased activation to be associated with increasing task difficulty predominantly the prefrontal cortex, parietal lobules, and cingulate gyrus for the stimulation phase. The spatial distribution of this network suggests similarities with the default mode network during the stimulation phase. Patterns of activation in the PFC were not strongly left-hemisphere dominant although a verbal stimulus was used, probably because short termmaintenance has not been confined to the rehearsal mechanisms of the articulatory loop.

Previous studies using this task have been based on very small numbers $(N<40)$ and have principally focused on younger subjects (ie $<30$ year-old) (Cairo et al., 2004; Chang, Crottaz-Herbette, \& Menon, 2007; Chen \& Desmond, 2005; Desmond, Gabrieli, Wagner, Ginier, \& Glover, 1997; Habeck et al., 2003, 2005; Holtzer et al., 2009; Marvel \& Desmond, 2010) or young vs healthy elderly subjects (Ansado, Oury, Nourane, Faure, \& Joanette, 2012; Zarahn et al., 2007), and used differing numbers of items (1-8 items) and types of encoding stimuli; letters (Ansado et al., 2013; Bunge, Ochsner, Desmond, Glover, \& Gabrieli, 2001; Habeck et al., 2005; Zarahn et al., 2006, 2007), shapes (Holtzer et al., 2009) or numbers (Adler et al., 2001; Portas et al., 1998) thus limiting comparisons between studies. Moreover, these studies have focused either on specific DIR task phases (Habeck et al., 2005;
Zarahn et al., 2006, 2007) or all phases together (Ansado et al. 2013; Bunge et al., 2001). It is thus not surprising that previous observations have been inconsistent.

In studies using tasks other than the DIR task, few have provided information focused on decreased networks, in either young subjects (Greicius \& Menon, 2004), comparing young vs healthy elderly subjects (Sambataro et al., 2010) or comparing healthy elderly subjects to subjects with mild cognitive impairment or Alzheimer's disease (Rombouts et al., 2005); no studies have to date specifically focused on elderly subjects. By assessing concomitantly increasing and decreasing activation as a function of increased load, and by exploring each phase of a DIR task in order to examine separately the different cognitive processes of working memory in a large and homogeneous sample of healthy elderly participants, this study has significantly refined and expanded knowledge of working memory-related networks in an age cohort particularly vulnerable to working memory changes.

Although the most fMRI studies examine right-handed subjects only, our sample was composed of right (91.7), left (3.6\%) and mixed $(4.7 \%)$ handed subjects. Studies have shown that the spatial distribution of neural networks is mainly symmetrical between left and right-handed subjects (Li et al., 2014; Pool, Eickhoff, Fink, \& Grefkes, 2014; Pujol, Deus, Losilla, \& Capdevila, 1999; Saenger \& Barrios, 2012). Consequently, in our study, we have included all participants regardless of handedness to ensure that our sample may be more exhaustive and representative of the general population of healthy elderly subjects.

\subsection{Increased task load effect}

The observations obtained in this study on a larger sample $(N=337)$ provide preliminary normative data for the study of 
Table 2

Increased activation associated with increasing task load.

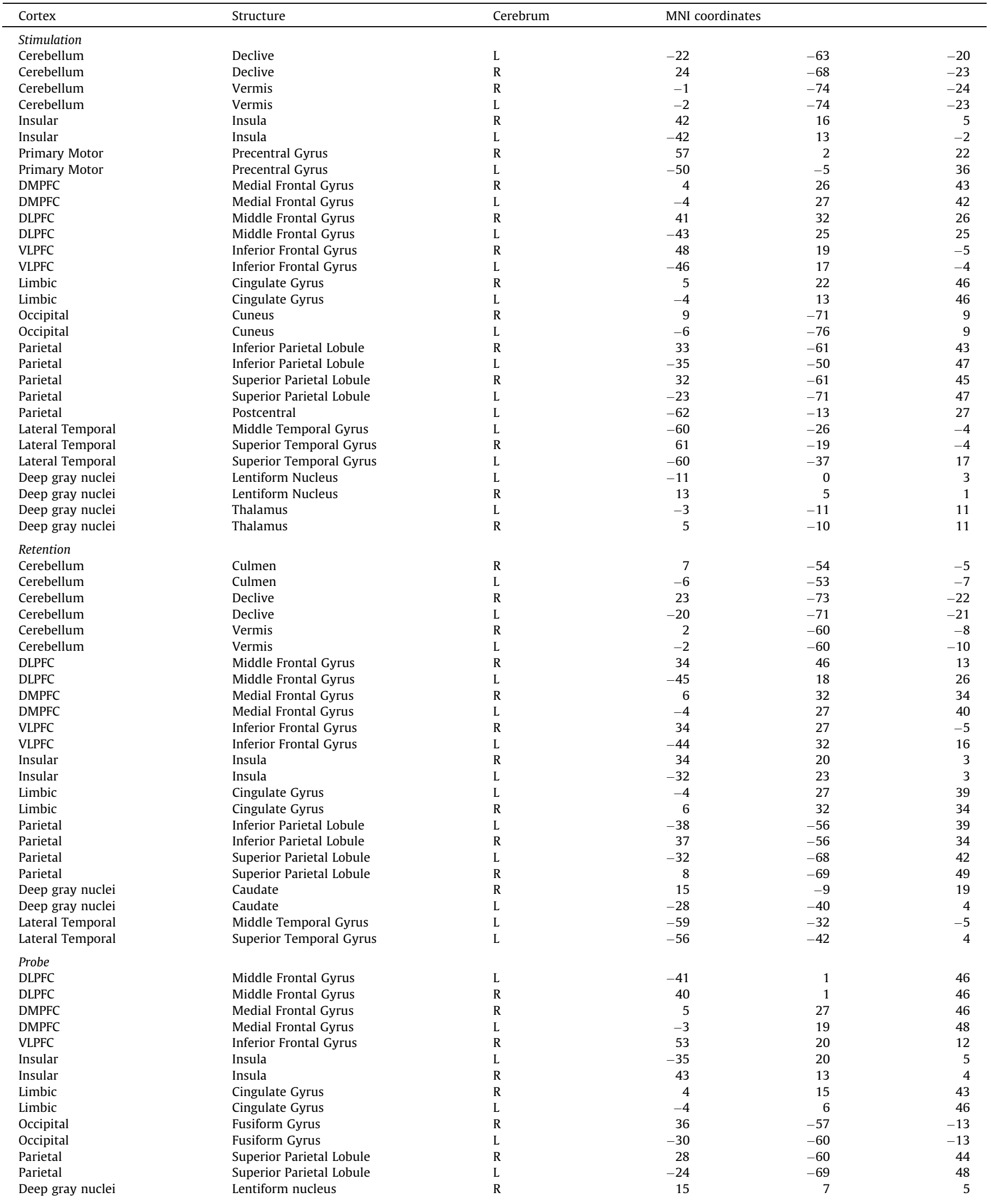


Table 2 (continued)

\begin{tabular}{|c|c|c|c|c|c|}
\hline Cortex & Structure & Cerebrum & MNI & & \\
\hline Deep gray nuclei & Lentiform nucleus & $\mathrm{L}$ & -13 & 4 & 3 \\
\hline Deep gray nuclei & Thalamus & $\mathrm{R}$ & 6 & -20 & 1 \\
\hline Deep gray nuclei & Thalamus & $\mathrm{L}$ & -5 & -22 & 1 \\
\hline
\end{tabular}

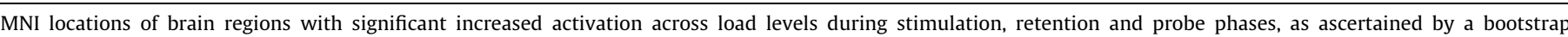
resampling test $(Z$ score $\geqslant 2.33)$.

Abbreviations. VLPFC: ventrolateral prefrontal cortex, DLPFC: dorsolateral prefrontal cortex, MPFC: medial prefrontal cortex, L: left, R: right.

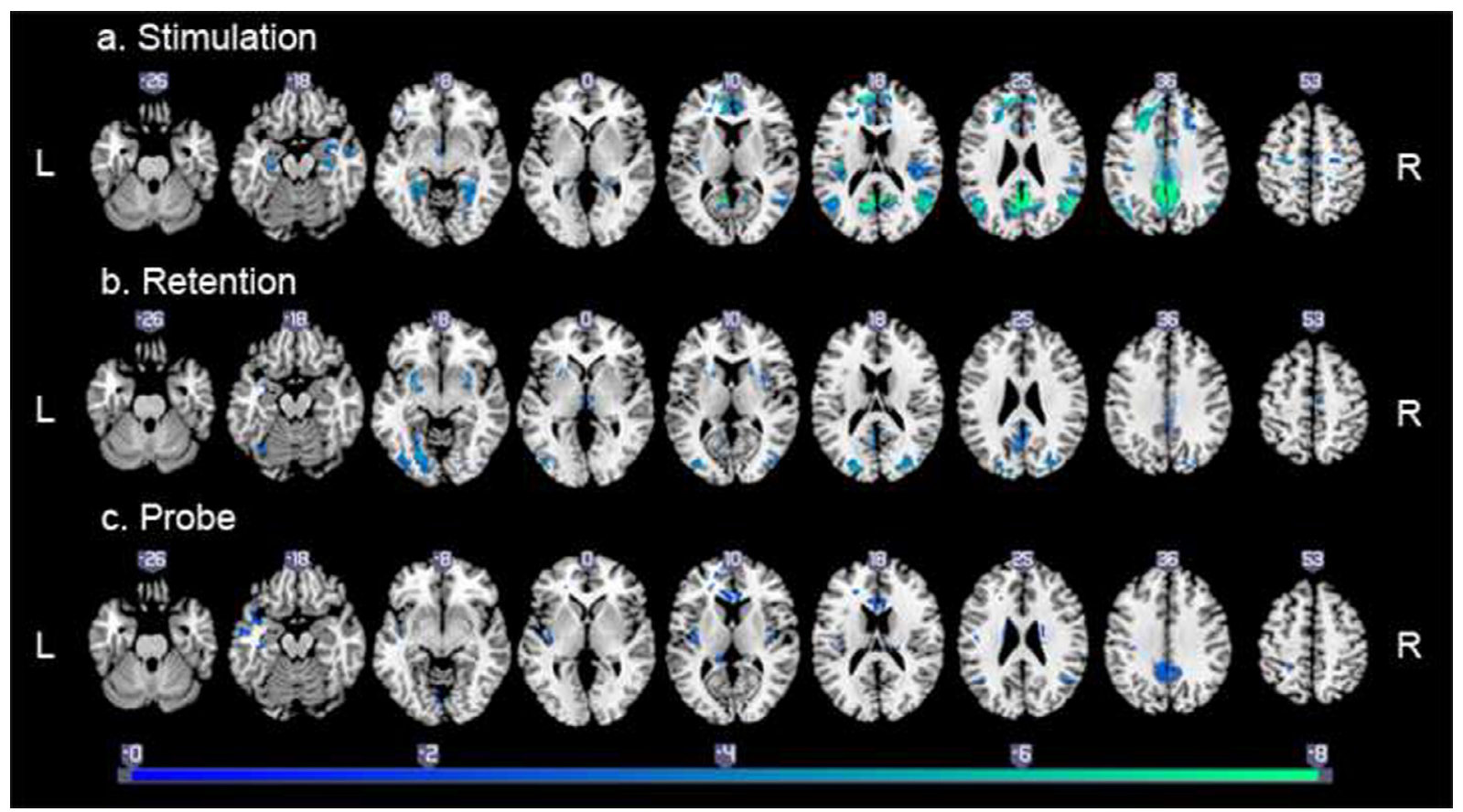

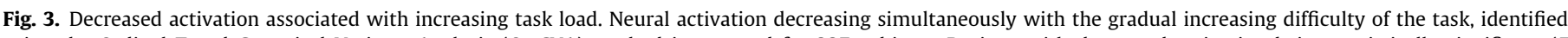

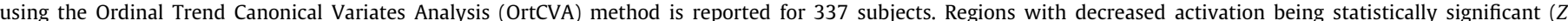

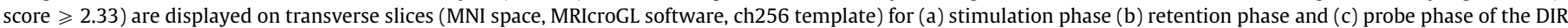

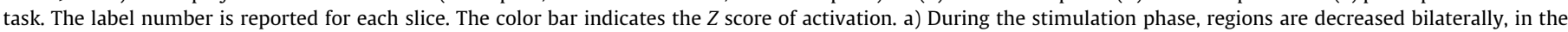

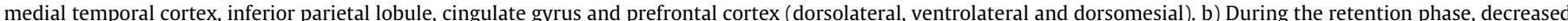

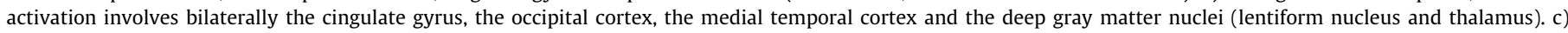

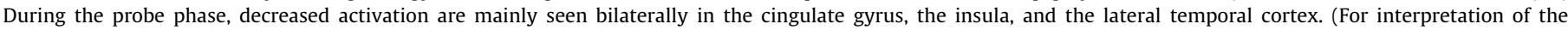
references to color in this figure legend, the reader is referred to the web version of this article.)

healthy aging, while data relating to response to task difficulty may also further inform future analyses relating to cognitive reserve through examination of inter-individual disparities in the recruitment of neural networks (Scarmeas \& Stern, 2003; Barnett, Salmond, Jones, \& Sahakian, 2006; Jones et al., 2011; Liu, Cai, Xue, Zhou, \& Wu, 2013; Murray et al., 2011; Stern, 2009).

We found increased activation simultaneously with the gradual increasing difficulty of the task in bilateral cerebellum, bilateral cingulate gyrus, left dorsolateral prefrontal cortex and left superior parietal lobule during the stimulation phase; bilateral cerebellum, right cingulate gyrus, right dorsolateral prefrontal cortex, bilateral inferior parietal lobule and left middle temporal gyrus during retention; and bilateral regions of ventrolateral and dorsolateral prefrontal cortex, insula and left thalamus during the probe phase. These findings are in accordance with those reported by only two studies (Habeck et al., 2003; Zarahn et al., 2007) assessing task load neural networks activation associated with DIR task of increasing difficulty. Furthermore, we observed activation in bilateral cerebellum during stimulation and retention phases, as previously reported by Chen and Marvel (Chen et al., 2013; Marvel \& Desmond, 2010) suggesting that the cerebellar regions are involved in rapid articulatory mechanism. The cerebellum may contribute to articulatory preparation and phonological storage processes during the stimulation phase and to refreshment of the phonological store during retention phase.

During memory tasks, previous studies have identified the involvement of both salience and central executive networks (Bressler \& Menon, 2010; Fecteau, Bell, \& Munoz, 2004; Menon \& Uddin, 2010; Sridharan, Levitin, \& Menon, 2008). These networks have been observed previously using resting-state fMRI (Bressler \& Menon, 2010; Chen et al., 2013; Damoiseaux et al., 2006; Menon \& Uddin, 2010; Seeley et al., 2007; Sridharan et al., 2008).

Several studies (Bressler \& Menon, 2010; Bunge et al., 2001; Cabeza \& Nyberg, 2000; Chen et al., 2013; Koechlin \& Summerfield, 2007; Menon \& Uddin, 2010; Müller \& Knight, 2006) have suggested that the central executive network is involved in high-level cognitive control and attentional processes by showing that the central executive network is activated during maintenance of information in working memory and during decision-making processes. The DIR task, combining working memory and decision-making processes, may thus be assumed to recruit the central executive network. The spatial distribution of the central executive network has been well described in the literature and appears to implicate bilateral dorsolateral and dorsomesial prefrontal cortex and bilateral lateral pari- 
Table 3

Decreased activation associated with increasing task load.

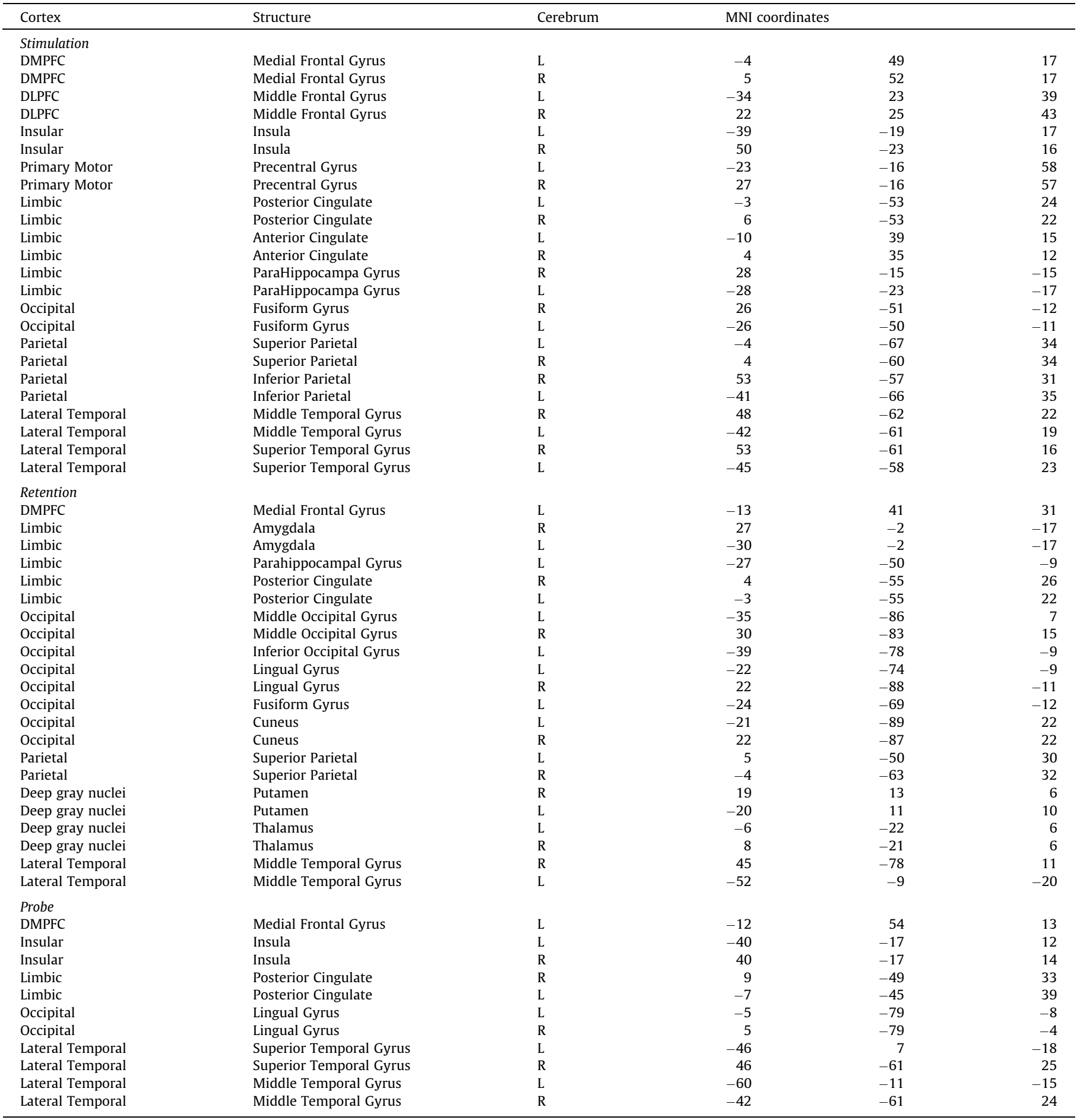

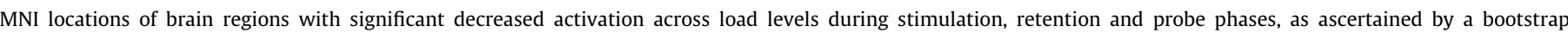
resampling test $(Z$ score $\geqslant 2.33$ ).

Abbreviations. VLPFC: ventrolateral prefrontal cortex, DLPFC: dorsolateral prefrontal cortex, MPFC: medial prefrontal cortex, L: left, R: right.

etal cortex (Menon \& Uddin, 2010; Sauseng, Klimesch, Schabus, \& Doppelmayr, 2005; Seeley et al., 2007; Sridharan et al., 2008). In our study, we have identified these regions in each phase of the task, with increasing activation simultaneously with the gradual increasing task difficulty (see Table 4).

In addition to the central executive network, the salience network has also been hypothesized to be involved in working memory, especially in cognitive processes involving monitoring, decision-making, and cognitive control (Bunge et al., 2001; Cabeza \& Nyberg, 2000; Chen et al., 2013; Crottaz-Herbette \& Menon, 2006; Johnston, Levin, Koval, \& Everling, 2007; Menon \& Uddin, 2010; Seeley et al., 2007). The spatial distribution of this network in younger persons has been observed to comprise bilateral regions of the insula and cingulate gyrus (Crottaz-Herbette \& Menon, 2006; Johnston et al., 2007; Uddin, 2015). These regions were observed in this elderly cohort to be implicated in each 
Table 4

Task load related networks of the delay item recognition task.

\begin{tabular}{|c|c|c|c|}
\hline & \multicolumn{3}{|c|}{ MNI coordinates $[x, y, z]$} \\
\hline & Stimulation & Retention & Probe \\
\hline \multicolumn{4}{|l|}{ Central executive network } \\
\hline $\begin{array}{l}\text { Dorsomesial prefrontal } \\
\text { cortex }\end{array}$ & {$[4,26,43]$} & {$[6,32,34]$} & {$[5,27,46]$} \\
\hline $\begin{array}{l}\text { Left dorsolateral } \\
\text { prefrontal cortex }\end{array}$ & {$[-42,24,28]$} & {$[-45,18,26]$} & {$[-41,1,46]$} \\
\hline $\begin{array}{l}\text { Right dorsolateral } \\
\text { prefrontal cortex }\end{array}$ & {$[41,32,26]$} & {$[34,46,13]$} & {$[40,1,46]$} \\
\hline Left parietal lobule & {$[-35,-50,47]$} & {$[-38,-56,39]$} & {$[-24,-69,48]$} \\
\hline Right parietal lobule & {$[33,-61,43]$} & {$[37,-56,39]$} & {$[28,-60,44]$} \\
\hline \multicolumn{4}{|l|}{ Salience network } \\
\hline Left cingulate gyrus & {$[-4,13,46]$} & {$[-4,27,39]$} & {$[-4,6,46]$} \\
\hline Right cingulate gyrus & {$[5,22,46]$} & {$[6,32,34]$} & {$[4,15,43]$} \\
\hline Left insula & {$[-42,13,-2]$} & {$[-32,23,3]$} & {$[-35,20,5]$} \\
\hline Right insula & {$[42,16,5]$} & {$[34,20,3]$} & {$[43,13,4]$} \\
\hline \multicolumn{4}{|l|}{ Default mode network } \\
\hline $\begin{array}{l}\text { Dorsomesial prefrontal } \\
\quad \text { cortex }\end{array}$ & {$[-4,49,17]$} & & \\
\hline $\begin{array}{l}\text { Superior parietal lobule } \\
\quad \text { - precuneus }\end{array}$ & {$[-3,-54,24]$} & & \\
\hline $\begin{array}{l}\text { Left temporal lateral } \\
\quad \text { cortex }\end{array}$ & {$[-48,-62,25]$} & & \\
\hline $\begin{array}{l}\text { Right temporal lateral } \\
\text { cortex }\end{array}$ & {$[48,-62,25]$} & & \\
\hline $\begin{array}{l}\text { Left inferior parietal } \\
\text { lobule }\end{array}$ & {$[50,56,25]$} & & \\
\hline $\begin{array}{l}\text { Right inferior parietal } \\
\text { lobule }\end{array}$ & {$[53,-47,25]$} & & \\
\hline
\end{tabular}

MNI locations of brain regions which composed nodes of neural networks during stimulation, retention and probe phases $(Z$ score $\geqslant 2.33)$. Central executive and salience networks showed increased activation across load levels over the three phases of the task. The default mode network showed decreased activation across load levels during stimulation phase.

phases of the task, with increasing activation simultaneously with the gradual increasing difficulty of the task (see Table 4).

However, we identified some differences between our results and previous studies (Habeck et al., 2003; Zarahn et al., 2007). Concerning additional activation not described previously, we observed, during the stimulation phase, additional activation in bilateral insula, bilateral precentral gyrus, right dorsolateral prefrontal cortex, bilateral ventrolateral prefrontal cortex, bilateral cuneus, bilateral inferior parietal lobule, right superior parietal lobule, left postcentral gyrus, left middle temporal gyrus, bilateral superior temporal gyrus and bilateral lentiform nucleus. During the retention phase, we observed supplementary activation in left dorsolateral prefrontal cortex, bilateral ventrolateral prefrontal cortex, bilateral insula, left cingulate gyrus, bilateral superior parietal lobule, bilateral caudate and left superior temporal gyrus. Finally, during the probe phase we observed additional activation in bilateral cingulate gyrus, bilateral fusiform gyrus, right lentiform nucleus, bilateral dorsomesial prefrontal cortex and bilateral superior parietal lobule. An explanation could stem from differences in age and performance of the groups included in previous studies. With regard to age, studies by Habeck et al. (2003) and Zarahn et al. (2007) included subjects who were younger than those in the present study. In both these studies subjects not surprisingly performed better (response time shortened by $100-400 \mathrm{~ms}$ ).The present study has been sufficiently powered to take into account age and performance effects.

We may thus hypothesize, that previously observed differences in observed activation may be largely attributable to betweenstudy heterogeneity in age and performance. The DIR task being effortless for younger persons, they may be expected to succeed and increase activation with increased difficulty more than older persons. This difference in activation could be related to the concept of neural efficiency in both groups.

On the other hand, previous studies (Habeck et al., 2003; Zarahn et al., 2007) identified regions that we were not able to reproduce. During the stimulation phase, previous work has identified activation in the right parahippocampus; during the retention phase, activation in the bilateral precentral gyrus; during the probe phase, bilaterally in the cerebellum. This could indicate a ceiling effect for increased neural activity in relation to increasing demands of the task. That is, irrespective of difficulty level, older individuals may reach a maximum neural activation level, which cannot then be further increased in response to task difficulty.

\subsection{Decreased task load effect}

Previous studies assumed that, increased activation in some brain regions occurs simultaneously with attenuation of activation in other regions, in order to perform the DIR task (Griebe et al., 2014; Mayberg et al., 1999; Simpson, Drevets, Snyder, Gusnard, \& Raichle, 2001a; Simpson, Drevets, Snyder, Gusnard, \& Raichle, $2001 b)$. The attenuated networks have been implicated in memory processes or interfering thoughts such as conscious awareness. Consistent with the second objective of the present study, we have identified networks with decreased activation associated with the increasing difficulty of the DIR task, depending on the phase of the task.

During the stimulation phase, we observed bilateral decreased activation in the middle and superior temporal gyrus, cingulate gyrus, parietal lobes, dorsolateral and ventrolateral prefrontal cortex. Previous studies (Amft, Bzdok, \& Laird, 2014; Bastin et al., 2012; Bluhm et al., 2011; Broyd et al., 2009; Buckner, AndrewsHanna, \& Schacter, 2008; Greicius \& Menon, 2004; Li, Mai, \& Liu, 2014; Sambataro et al., 2010) suggested that these regions are functionally connected in the Default Mode Network (DMN).

In the present study, the spatial distribution of regions with decreased activation suggests implication of the DMN. This finding is consistent with studies in which DMN has been shown to decrease during cognitive tasks, especially during passive sensory tasks (Greicius \& Menon, 2004), verbal fluency tasks (Dong et al., 2012), verb generation task (Persson, Lustig, Nelson, \& ReuterLorenz, 2007) or visual encoding and non-spatial working memory tasks (Rombouts et al., 2005). DMN has never been reported in a DIR task and this is the first study to highlight DMN decreased activation simultaneously with the gradual increasing difficulty of a DIR task during the stimulation phase.

\subsection{Relationship between increased and decreased task load effect}

In brief, when the difficulty of the DIR task increases, we observed simultaneously increased activation in salience and central executive networks and decreased activation in DMN (Fig. 4 and Table 4). Previous studies have suggested that the salience network serves to initiate dynamic switching between the central executive network and DMN (Bressler \& Menon, 2010; Habeck et al., 2005; Menon \& Uddin, 2010; Palaniyappan \& Liddle, 2012; Pochon et al., 2002).

\subsection{Limitations of the present study}

A limitation of the present study was our inability to explore the involvement of the cerebellum due to a limited acquisition field. Furthermore, we analyzed increased and decreased activation associated with increasing task load on the basis of a linear model, in accordance with previous studies. However, some authors 


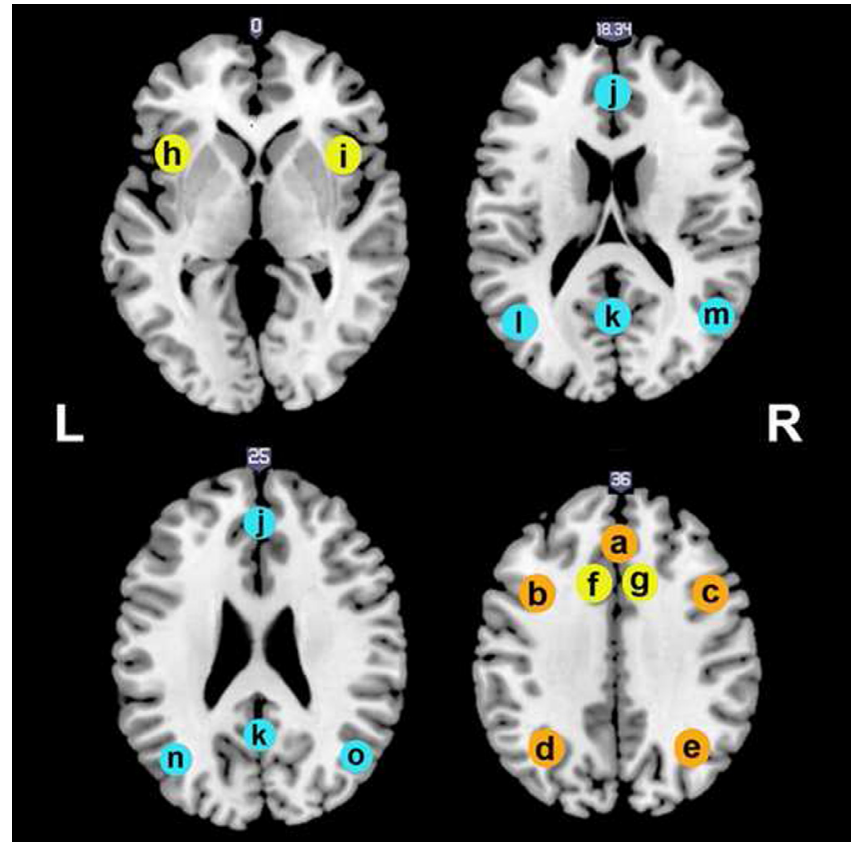

Fig. 4. Task load related networks of the delay item recognition task. We suggest that neural networks implicated in working memory functioning in an elderly cohort are distributed in 3 distinct networks: salience and central executive networks which increased activation is associated with increasing difficulty of the DIR task and the default mode network which is related to task load decreased activation. Regions have been identified using Ordinal Trend Canonical Variates Analysis (OrtCVA) method and have been schematized on transverse slices (MNI space, MRIcroGL software, ch256 template). The central executive network (orange) is composed of (a) dorsomesial prefrontal cortex, (b) left dorsolateral prefrontal cortex, (c) right dorsolateral prefrontal cortex, (d) left parietal lobule and (e) right parietal lobule. The salience network (yellow) is composed of (f) left cingulate gyrus, (g) right cingulate gyrus, (h) left insula, (i) right insula. The default mode network (blue) is composed of $(\mathrm{j})$ dorsomesial prefrontal cortex, (k) superior parietal lobule - precuneus, (l) left temporal lateral cortex, (m) right temporal lateral cortex, (n) left inferior parietal lobule and (o) right inferior parietal lobule. (For interpretation of the references to color in this figure legend, the reader is referred to the web version of this article.)

suggest that a quadratic model may be more appropriate (Kirschen, Chenc, Schraedley-Desmond, \& Desmond, 2005).

\section{Conclusion}

Our results suggest that neural networks implicated in working memory functioning in an elderly cohort implicate two distinct networks: salience and central executive. Our results suggest an increased activation in salience and central executive networks and a decreased activation in DMN. Further research is required to determine whether disease-related modifications in these networks and their relation to cognitive reserve may explain the clinical differences observed between individuals.

\section{Acknowledgments}

We thank all participants of the CRESCENDO Study and the CRESCENDO research team comprising research scientists, statisticians, study coordinators, neuropsychologists, general practitioners, data managers, administrative assistants and data entry staff, whom together made the study possible.

This CRESCENDO study was carried out with the financial support of the ANR - Agence Nationale de la Recherche (MALZ-007-01) - The French National Research Agency - and the grants "Chercheur d'Avenir" (R12028FF) and ARPE (Aide à la Recherche en Partenariat avec les Entreprises) (RPH12007F) allocated by the Languedoc Roussillon administrative regional district (France).

\section{Appendix A. Supplementary material}

Supplementary data associated with this article can be found, in the online version, at http://dx.doi.org/10.1016/j.nlm.2015.10.002.

\section{References}

Adler, C. M., Sax, K. W., Holland, S. K., Schmithorst, V., Rosenberg, L., \& Strakowski, S. M. (2001). Changes in neuronal activation with increasing attention demand in healthy volunteers: An fMRI study. Synapse, 42(4), 266-272. http://dx.doi.org/ 10.1002/syn.1112 [New York, NY].

Akbaraly, T. N . Portet, F. Fustinoni, S., Dartigues, J.-F Artero, S, Rouaud, O , Berr, C. (2009). Leisure activities and the risk of dementia in the elderly: Results from the three-city study. Neurology, 73(11), 854-861. http://dx.doi.org/10.1212/ WNL.0b013e3181b7849b.

Amft, M., Bzdok, D., \& Laird, A. R. (2014). Definition and characterization of an extended social-affective default network. Brain Structure and Function. http:// dx.doi.org/10.1007/s00429-013-0698-0.

American Psychiatric Association (2000). Diagnostic and statistical manual of mental disorders, (4th ed., text revision). Washington, DC: American Psychiatric Association.

Ansado, J., Oury, M., Nourane, E., Deslauriers, J., Jubault, T., Faure, S., et al. (2013). Coping with task demand in aging using neural compensation and neural reserve triggers primarily intra-hemispheric-based neurofunctional reorganization. Neuroscience Research. http://dx.doi.org/10.1016/j.neures.2013.01.012. février.

Ansado, J., Oury, M., Nourane, E., Faure, S., \& Joanette, Y. (2012). Load-dependent posterior-anterior shift in aging in complex visual selective attention situations. Brain Research, 1454(mai), 14-22. http://dx.doi.org/10.1016/j. brainres.2012.02.061.

Ashburner, J. (2007). A fast diffeomorphic image registration algorithm. NeuroImage, 38(1), 95-113. http://dx.doi.org/10.1016/j.neuroimage.2007. 07.007.

Ashburner, J. (2012). SPM: A history. NeuroImage, 62(2), 791-800. http://dx.doi.org/ 10.1016/j.neuroimage.2011.10.025.

Baddeley, A. (1988). Working memory, Oxford University Press, Oxford 1986. No. of Pages: 289. Applied Cognitive Psychology, 2(2), 166-168. http://dx.doi.org/ $10.1002 /$ acp.2350020209.

Baddeley, A. (2012). Working memory: Theories, models, and controversies. Annual Review of Psychology, 63, 1-29. http://dx.doi.org/10.1146/annurev-psych120710-100422.

Baddeley, A. D., Bressi, S., Sala, S. D., Logie, R., \& Spinnler, H. (1991). The decline of working memory in Alzheimer's disease. A Longitudinal study. Brain: A Journal of Neurology, 114(Pt 6), 2521-2542. décembre.

Barnett, J. H., Salmond, C. H., Jones, P. B., \& Sahakian, B. J. (2006). Cognitive reserve in neuropsychiatry. Psychological medicine, 36(8), 1053-1064. http://dx.doi.org/ 10.1017/S0033291706007501.

Bastin, C., Yakushev, I., Bahri, M. A., Fellgiebel, A., Eustache, F., Landeau, B., et al. (2012). Cognitive reserve impacts on inter-individual variability in resting-state cerebral metabolism in normal aging. NeuroImage, 63(2), 713-722. http://dx. doi.org/10.1016/j.neuroimage.2012.06.074.

Bluhm, R. L., Richard, C. C., McFarlane, A. C., Moores, K. A., Shaw, M. E., \& Lanius, R. A (2011). Default network connectivity during a working memory task. Human Brain Mapping, 32(7), 1029-1035. http://dx.doi.org/10.1002/hbm.21090.

Bressler, S. L., \& Menon, V. (2010). Large-scale brain networks in cognition: Emerging methods and principles. Trends in Cognitive Sciences, 14(6), 277-290. http://dx.doi.org/10.1016/j.tics.2010.04.004.

Broyd, S. J., Demanuele, C., Debener, S., Helps, S. K., James, C. J., \& Sonuga-Barke, E. J. S. (2009). Default-mode brain dysfunction in mental disorders: A systematic review. Neuroscience and Biobehavioral Reviews, 33(3), 279-296. http://dx.doi. org/10.1016/j.neubiorev.2008.09.002

Buckner, R. L. Andrews-Hanna, J. R. \& Schacter, D. L. (2008). The Brain's default network: Anatomy, function, and relevance to disease. Annals of the New York Academy of Sciences, 1124(mars), 1-38. http://dx.doi.org/10.1196/ annals.1440.011.

Bunge, S. A., Ochsner, K. N., Desmond, J. E., Glover, G. H., \& Gabrieli, J. D. E. (2001) Prefrontal regions involved in keeping information in and out of mind. Brain, 124(10), 2074-2086. http://dx.doi.org/10.1093/brain/124.10.2074.

Burnham, K. P., \& Anderson, D. R. (2004). Model selection and multimodel inference. New York, NY: Springer New York. <http://link.springer.com/10.1007/b97636>.

Cabeza, R., \& Nyberg, L. (2000). Imaging cognition II: An empirical review of 275 PET and fMRI studies. Journal of Cognitive Neuroscience, 12(1), 1-47.

Cairo, T. A., Liddle, P. F., Woodward, T. S., \& Ngan, E. T. C. (2004). The influence of working memory load on phase specific patterns of cortical activity. Brain Research. Cognitive Brain Research, 21(3), 377-387. http://dx.doi.org/10.1016/j. cogbrainres.2004.06.014.

Chang, C., Crottaz-Herbette, S., \& Menon, V. (2007). Temporal dynamics of basal ganglia response and connectivity during verbal working memory. NeuroImage, 34(3), 1253-1269. http://dx.doi.org/10.1016/j.neuroimage.2006.08.056.

Chen, S. H. A., \& Desmond, J. E. (2005). Temporal dynamics of cerebro-cerebellar network recruitment during a cognitive task. Neuropsychologia, 43(9), 1227-1237. http://dx.doi.org/10.1016/j.neuropsychologia.2004.12.015. 
Chen, A. C., Desmond, J., Chang, C., Bradley, T., Zhou, Z.-W., Williams, L. M., ... Etkin, A. (2013). Causal interactions between fronto-parietal central executive and default-mode networks in humans. Proceedings of the National Academy of Sciences (novembre). http://dx.doi.org/10.1073/pnas.1311772110. 201311772.

Christoff, K., Gordon, A. M., Smallwood, J., Smith, R., \& Schooler, J. W. (2009). Experience sampling during fMRI reveals default network and executive system contributions to mind wandering. Proceedings of the National Academy of Sciences (mai). http://dx.doi.org/10.1073/pnas.0900234106, pnas.0900234106.

Coltheart, M. (2006). What has functional neuroimaging told us about the mind (so far)? Cortex, 42(3), 323-331.

Crottaz-Herbette, S., \& Menon, V. (2006). Where and when the anterior cingulate cortex modulates attentional response: Combined fMRI and ERP evidence. Journal of Cognitive Neuroscience, 18(5), 766-780. http://dx.doi.org/10.1162/ jocn.2006.18.5.766.

Curtis, C. E., \& D’Esposito, M. (2003). Persistent activity in the prefrontal cortex during working memory. Trends in Cognitive Sciences, 7(9), 415-423.

D'Esposito, M., Deouell, L. Y., \& Gazzaley, A. (2003). Alterations in the BOLD fMRI signal with ageing and disease: A challenge for neuroimaging. Nature Reviews Neuroscience, 4(11), 863-872. http://dx.doi.org/10.1038/nrn1246.

Damoiseaux, J. S., Rombouts, S. A. R. B., Barkhof, F., Scheltens, P., Stam, C. J., Smith, S. M., et al. (2006). Consistent resting-state networks across healthy subjects. Proceedings of the National academy of Sciences of the United States of America, 103(37), 13848-13853. http://dx.doi.org/10.1073/pnas.0601417103.

Desmond, J. E., Gabrieli, J. D., Wagner, A. D., Ginier, B. L., \& Glover, G. H. (1997). Lobular patterns of cerebellar activation in verbal working-memory and fingertapping tasks as revealed by functional MRI. The Journal of Neuroscience. The Official Journal of the Society for Neuroscience, 17(24), 9675-9685.

Dong, L., Shen, Y., Lei, X., Luo, C., Li, Q., Wu, W., ... Li, C. (2012). The heterogeneity of aging brain: Altered functional connectivity in default mode network in older adults during verbal fluency tests. Chinese Medical Journal, 125(4), 604-610.

Fecteau, J. H., Bell, A. H., \& Munoz, D. P. (2004). Neural correlates of the automatic and goal-driven biases in orienting spatial attention. Journal of Neurophysiology, 92(3), 1728-1737. http://dx.doi.org/10.1152/jn.00184.2004.

Folstein, M. F., Folstein, S. E., \& McHug, P. R. (1975). “Mini-Mental State”. A practical method for grading the cognitive state of patients for the clinician. Journal of Psychiatric Research, 12(3), 189-198.

Friston, K. J., Holmes, A. P., Worsley, K. J., Poline, J.-P., Frith, C. D., \& Frackowiak, R. S. J. (1994). Statistical parametric maps in functional imaging: A general linear approach. Human Brain Mapping, 2(4), 189-210. http://dx.doi.org/10.1002/ hbm.460020402.

Fuster, J. M. (1973). Unit activity in prefrontal cortex during delayed-response performance. Neuronal correlates of transient memory. Journal of Neurophysiology, 36(1), 61-78.

Greicius, M. D., Krasnow, B., Reiss, A. L., \& Menon, V. (2003). Functional connectivity in the resting brain: A network analysis of the default mode hypothesis. Proceedings of the National academy of Sciences of the United States of America, 100(1), 253-258. http://dx.doi.org/10.1073/pnas.0135058100.

Greicius, M. D., \& Menon, V. (2004). Default-mode activity during a passive sensory task: Uncoupled from deactivation but impacting activation. Journal of Cognitive Neuroscience, 16(9), 1484-1492. http://dx.doi.org/10.1162/0898929042568532.

Griebe, M., Michael, A., Hirsch, J. G., Achtnichts, L., Hennerici, M. G., Gass, A., et al. (2014). Reduced functional reserve in patients with age-related white matter changes: A preliminary fmri study of working memory. PLOS ONE, 9(8), e103359. http://dx.doi.org/10.1371/journal.pone.0103359.

Gusnard, D. A., \& Raichle, M. E. (2001). Searching for a baseline: Functional imaging and the resting human brain. Nature Reviews Neuroscience, 2(10), 685-694. http://dx.doi.org/10.1038/35094500.

Habeck, C., Hilton, H. J., Zarahn, E., Flynn, J., Moeller, J., \& Stern, Y. (2003). Relation of cognitive reserve and task performance to expression of regional covariance networks in an event-related fMRI study of nonverbal memory. NeuroImage, 20 (3), 1723-1733.

Habeck, C., Rakitin, B. C., Moeller, J., Scarmeas, N., Zarahn, E., Brown, T., et al. (2005). An event-related fMRI study of the neural networks underlying the encoding, maintenance, and retrieval phase in a delayed-match-to-sample task. Brain Research. Cognitive Brain Research, 23(2-3), 207-220. http://dx.doi.org/10.1016/ j.cogbrainres.2004.10.010.

Holtzer, R., Rakitin, B. C., Steffener, J., Flynn, J., Kumar, A., \& Stern, Y. (2009). Age effects on load-dependent brain activations in working memory for novel material. Brain Research, 1249, 148-161. http://dx.doi.org/10.1016/j. brainres.2008.10.009. janvier.

Johnston, K., Levin, H. M., Koval, M. J., \& Everling, S. (2007). Top-down control-signal dynamics in anterior cingulate and prefrontal cortex neurons following task switching. Neuron, 53(3), 453-462. http://dx.doi.org/10.1016/j. neuron.2006.12.023.

Jones, R. N., Manly, J., Glymour, M. M., Rentz, D. M., Jefferson, A. L., \& Stern, Y. (2011) Conceptual and measurement challenges in research on cognitive reserve. Journal of the International Neuropsychological Society: JINS, 17(4), 593-601. http://dx.doi.org/10.1017/S1355617710001748.

Kirschen, M. P., Chenc, S. H. A., Schraedley-Desmond, P., \& Desmond, J. E. (2005). Load- and practice-dependent increases in cerebro-cerebellar activation in verbal working memory: An fMRI study. NeuroImage, 24(2), 462-472. http://dx. doi.org/10.1016/j.neuroimage.2004.08.036.

Koechlin, E., \& Summerfield, C. (2007). An information theoretical approach to prefrontal executive function. Trends in Cognitive Sciences, 11(6), 229-235. http://dx.doi.org/10.1016/j.tics.2007.04.005.
Li, W., Mai, X., \& Liu, C. (2014). The default mode network and social understanding of others: What do brain connectivity studies tell us. Frontiers in Human Neuroscience, 8, 74. http://dx.doi.org/10.3389/fnhum.2014.00074.

Li, M., Wang, J., Liu, W., Chen, H., Lu, F., Wu, G., ... Chen, H. (2014). Handedness- and brain size-related efficiency differences in small-world brain networks: A resting-state functional magnetic resonance imaging study. Brain Connectivity, 5 (4), 259-265. http://dx.doi.org/10.1089/brain.2014.0291.

Linden, D. E. J., Bittner, R. A., James, L. M., Waltz, A., Kriegeskorte, N., Goebel, R., .. Munk, M. H. J. (2003). Cortical capacity constraints for visual working memory: Dissociation of fMRI load effects in a fronto-parietal network. Neurolmage, 20 (3), 1518-1530.

Liu, Y., Cai, Z. L., Xue, S., Zhou, X., \& Wu, F. (2013). Proxies of cognitive reserve and their effects on neuropsychological performance in patients with mild cognitive impairment. Journal of Clinical Neuroscience. Official Journal of the Neurosurgical Society of Australasia, 20(4), 548-553. http://dx.doi.org/10.1016/j. jocn.2012.04.020.

Manoach, D. S., Greve, D. N., Lindgren, K. A., \& Dale, A. M. (2003). Identifying regional activity associated with temporally separated components of working memory using event-related functional MRI. Neurolmage, 20(3), 1670-1684.

Marvel, C. L., \& Desmond, J. E. (2010). The contributions of cerebro-cerebellar circuitry to executive verbal working memory. Cortex; A Journal Devoted to the Study of the Nervous System and Behavior, 46(7), 880-895. http://dx.doi.org/ 10.1016/j.cortex.2009.08.017.

Mayberg, H. S., Liotti, M., Brannan, S. K., McGinnis, S., Mahurin, R. K., Jerabek, P. A., et al. (1999). Reciprocal limbic-cortical function and negative mood: Converging PET findings in depression and normal sadness. The American Journal of Psychiatry, 156(5), 675-682.

McKhann, G., Drachman, D., Folstein, M., Katzman, R., Price, D., \& Stadlan, E. M. (1984). Clinical diagnosis of Alzheimer's disease: Report of the NINCDS-ADRDA Work Group under the Auspices of Department of Health and Human Services Task Force on Alzheimer's Disease. Neurology, 34(7), 939-944.

Menon, V., \& Uddin, L. Q. (2010). Saliency, switching, attention and control: A network model of insula function. Brain Structure $\mathcal{E}$ Function, 214(5-6), 655-667. http://dx.doi.org/10.1007/s00429-010-0262-0.

Moeller, J. R., \& Habeck, C. (2006). Reciprocal benefits of mass-univariate and multivariate modeling in brain mapping: Applications to event-related functional MRI, H2 150-, and FDG-PET. International Journal of Biomedical Imaging. http://dx.doi.org/10.1155/IJBI/2006/79862.

Müller, N. G., \& Knight, R. T. (2006). The functional neuroanatomy of working memory: Contributions of human brain lesion studies. Neuroscience, 139(1), 51-58. http://dx.doi.org/10.1016/j.neuroscience.2005.09.018.

Murray, A. D., Staff, R. T., McNeil, C. J., Salarirad, S., Ahearn, T. S., Mustafa, N., et al (2011). The balance between cognitive reserve and brain imaging biomarkers of cerebrovascular and Alzheimer's diseases. Brain: A Journal of Neurology, 134(Pt 12), 3687-3696. http://dx.doi.org/10.1093/brain/awr259.

Nee, D. E., Brown, J. W., Askren, M. K., Berman, M. G., Demiralp, E., Krawitz, A., et al. (2013). A meta-analysis of executive components of working memory. Cerebral Cortex (New York, NY: 1991), 23(2), 264-282. http://dx.doi.org/10.1093/cercor/ bhs007.

Nystrom, L. E., Braver, T. S., Sabb, F. W., Delgado, M. R., Noll, D. C., \& Cohen, J. D (2000). Working memory for letters, shapes, and locations: fMRI evidence against stimulus-based regional organization in human prefrontal cortex Neurolmage, 11(5 Pt 1), 424-446. http://dx.doi.org/10.1006/nimg.2000.0572.

Palaniyappan, L., \& Liddle, P. F. (2012). Does the salience network play a cardinal role in psychosis? An emerging hypothesis of insular dysfunction. Journal of Psychiatry \& Neuroscience JPN, 37(1), 17-27. http://dx.doi.org/10.1503/ jpn.100176.

Park, D. C., Smith, A. D., Lautenschlager, G., Earles, J. L., Frieske, D., Zwahr, M., et al (1996). Mediators of long-term memory performance across the life span. Psychology and Aging, 11(4), 621-637.

Persson, J., Lustig, C., Nelson, J. K., \& Reuter-Lorenz, P. A. (2007). Age differences in deactivation: A link to cognitive control? Journal of Cognitive Neuroscience, 19(6), 1021-1032. http://dx.doi.org/10.1162/jocn.2007.19.6.1021.

Pochon, J. B., Levy, R., Fossati, P., Lehericy, S., Poline, J. B., Pillon, B., ... Dubois, B. (2002). The neural system that bridges reward and cognition in humans: An fMRI study. Proceedings of the National Academy of Sciences, 99(8), 5669-5674. http://dx.doi.org/10.1073/pnas.082111099.

Pool, E., Eickhoff, S., Fink, G., \& Grefkes, C. (2014). Functional resting-state connectivity of the human motor network: Differences between right- and left-handers. Klinische Neurophysiologie, 45(01). http://dx.doi.org/10.1055/s0034-1371279.

Portas, C. M., Rees, G., Howseman, A. M., Josephs, O., Turner, R., \& Frith, C. D. (1998) A specific role for the thalamus in mediating the interaction of attention and arousal in humans. The Journal of Neuroscience. The Official Journal of the Society for Neuroscience, 18(21), 8979-8989.

Pujol, J., Deus, J., Losilla, J. M., \& Capdevila, A. (1999). Cerebral lateralization of language in normal left-handed people studied by functional MRI. Neurology, 52 (5). http://dx.doi.org/10.1212/WNL.52.5.1038. 1038-1038.

Román, G. C., Tatemichi, T. K., Erkinjuntti, T., Cummings, J. L., Masdeu, J. C., Garcia, J. H., ... Hofman, A. (1993). Vascular dementia: Diagnostic criteria for research studies. Report of the NINDS-AIREN International Workshop. Neurology, 43(2), $250-260$.

Rombouts, S., Barkhof, F., Goekoop, R., Stam, C. J., \& Scheltens, P. (2005). Altered resting state networks in mild cognitive impairment and mild Alzheimer's 
disease: An fMRI study. Human Brain Mapping, 26(4), 231-239. http://dx.doi. org/10.1002/hbm.20160.

Rottschy, C., Caspers, S., \& Roski, C. (2013). Differentiated parietal connectivity of frontal regions for "what" and "where" memory. Brain Structure and Function, 218, 1551-1567. http://dx.doi.org/10.1007/s00429-012-0476-4.

Saenger, V. M., \& Barrios, F. A. (2012). Hemispheric asymmetries of functional connectivity and grey matter volume in the default mode network. Neuropsychologia, 50(7), 1308-1315. http://dx.doi.org/10.1016/j. neuropsychologia.2012.02.014.

Sambataro, F., Murty, V. P., Callicott, J. H., Tan, H. Y., Das, S., Weinberger, D. R., et al (2010). Age-related alterations in default mode network: Impact on working memory performance. Neurobiology of Aging, 31(5), 839-852. http://dx.doi.org/ 10.1016/j.neurobiolaging.2008.05.022.

Sauseng, P., Klimesch, W., Schabus, M., \& Doppelmayr, M. (2005). Fronto-parietal EEG coherence in theta and upper alpha reflect central executive functions of working memory. International Journal of Psychophysiology, EEG Coherence, 57 (2), 97-103. http://dx.doi.org/10.1016/j.ijpsycho.2005.03.018.

Scarmeas, N., \& Stern, Y. (2003). Cognitive reserve and lifestyle. Journal of Clinical and Experimental Neuropsychology, 25(5), 625-633. http://dx.doi.org/10.1076/ jcen.25.5.625.14576.

Seeley, W., Menon, V., Schatzberg, A. F., Keller, J., Glover, G. H., Kenna, H., et al (2007). Dissociable intrinsic connectivity networks for salience processing an executive control. The Journal of Neuroscience: The official journal of the Society for Neuroscience, 27(9), 2349-2356. http://dx.doi.org/10.1523/JNEUROSCI.558706.2007.

Simpson, J. R. Drevets, W. C. Snyder, A. Z., Gusnard, D. A. \& Raichle, M. E. (2001a). Emotion-induced changes in human medial prefrontal cortex: II. During anticipatory anxiety. Proceedings of the National Academy of Sciences, 98(2), 688-693. http://dx.doi.org/10.1073/pnas.98.2.688.
Simpson, J. R., Drevets, W. C., Snyder, A. Z., Gusnard, D. A., \& Raichle, M. E. (2001b). Emotion-induced changes in human medial prefrontal cortex: I. During cognitive task performance. Proceedings of the National Academy of Sciences, 98 (2), 683-687. http://dx.doi.org/10.1073/pnas.98.2.683.

Smith, E. E. Jonides, J. Marshuetz, C. \& Koeppe, R. A. (1998). Components of verbal working memory: Evidence from neuroimaging. Proceedings of the National academy of Sciences of the United States of America, 95(3), 876-882.

Sridharan, D., Levitin, D. J., \& Menon, V. (2008). A critical role for the right frontoinsular cortex in switching between central-executive and default-mode networks. Proceedings of the National academy of Sciences of the United States of America, 105(34), 12569-12574. http://dx.doi.org/10.1073/pnas.0800005105.

Stern, Y. (2009). Cognitive reserve. Neuropsychologia, 47(10), 2015-2028. http://dx. doi.org/10.1016/j.neuropsychologia.2009.03.004.

Sternberg, S. (1966). High-speed scanning in human memory. Science (New York, N. Y.), 153(3736), 652-654.

The 3C Study Group (2003). Vascular factors and risk of dementia: Design of the three-city study and baseline characteristics of the study population. Neuroepidemiology, 22(6), 316-325. http://dx.doi.org/10.1159/000072920.

Uddin, L. O. (2015). Salience processing and insular cortical function and dysfunction. Nature Reviews Neuroscience, 16(1), 55-61. http://dx.doi.org/ 10.1038/nrn3857.

Zarahn, E., Rakitin, B. C., Abela, D., Flynn, J., \& Stern, Y. (2006). Distinct spatial patterns of brain activity associated with memory storage and search. NeuroImage, $\quad 33(2), \quad 794-804 . \quad$ http://dx.doi.org/10.1016/j. neuroimage.2006.07.020

Zarahn, E. Rakitin, B. C., Abela, D. Flynn, J \& Stern, Y (2007). Age-related changes in brain activation during a delayed item recognition task. Neurobiology of Aging, 28(5), 784-798. http://dx.doi.org/10.1016/j.neurobiolaging.2006.03.002. 